\title{
Identification of Promising Castor Hybrid Combinations by Principal Component Analysis
}

\author{
Yamanura* and R. Mohan Kumar
}

All India Co-ordinated Research Project on Castor, Zonal Agricultural research Station, University of Agricultural Sciences, GKVK, Bengaluru - 560 065, India

*Corresponding author

\section{A B S T R A C T}

\section{Keywords \\ Castor, Cluster distance, Genetic diversity, PCA analysis, Variability}

\section{Article Info}

Accepted: 10 August 2020 Available Online: 10 September 2020
In order to find out the selection criteria thirty three genotypes were evaluated during kharif 2019-20 which includes 20 hybrids, 12 parents and a check (ICH-66). Data was subjected to principal component analysis (PCA) to reduce the number of variables in the original data set to a more significant set of variables, while maintaining maximum information. In the present investigation PCA was performed for 12 quantitative traits which yielded five PCs among them only four PCs exhibited more than 1.0 eigen values and showed about $84.34 \%$ variability. The PC 1 explained total variation $33.88 \%$ followed by PC 2 with $27.53 \%$, PC 3 with $13.12 \%$ and PC 4 with $9.81 \%$. The whole thirty three genotypes divided into eight main clusters. Cluster I consist of 19 genotype which was found to be a largest cluster had sub clusters from A to $\mathrm{O}$ followed by Cluster II had seven genotypes which divided into five sub clusters. Whereas, cluster III, IV, VI, VII and VIII consists of one genotype in each clusters and they had solitary entries Viz. DCS-120, DCS-102, ICH-66, DCS-108 and DCS-89 respectively. Cluster V also grouped as solitary but had ICH-1090 and ICH-326 genotypes. Based on values of inter cluster distance, it was found that the highest divergence occurred between cluster II and V (156.96) followed by cluster V and VIII (138.08),cluster I and VIII (110.42) indicating the wider genetic diversity between genotypes of these groups.

\section{Introduction}

Castor bean (Ricinus communis L.) is a tropical plant with high tolerance to drought and high-temperatures. It is one of the most important non-edible oilseed crops in the world. It is generally distributed in the tropical, sub-tropical and warm temperate zones (Weiss, 2000), it plays an important economic and social role, particularly due to its oil production potential (Costa et al.,
2010). Castor oil is obtained by pressing its seeds, which is used in the manufacturing of several products such as soaps, lubricants, hydraulic and brake fluids, dyes, and pharmaceuticals (Scholz and Silva, 2008). Oil content varies between 48 and $60 \%$ and is comprised of 80 to $90 \%$ ricinoleic acid, a monounsaturated, 18-carbon fatty acid with a hydroxyl functional group on the 12th carbon, which makes it more polar than most fats (Beltrão et al., 2008). There has been 
increasing interest in castor oil production due to its market value. As a result, cultivation has expanded to different regions in the country creating the need for the development of cultivars more adapted to a wide range of environmental condition, which allows farmers to better exploit the crop commercially (Costa et al., 2006).

However, the identification of superior genotypes in a breeding program is not a quick and simple task, and breeders should be aware of more suitable and efficient methods for evaluating crop performance. Genotypebased selection studies are traditionally described through univariate statistical analyses. Nevertheless, such approach may compromise interpretations and conclusions by not exploiting the dependence among variables. Moreover, selection based on one or a few traits often leads to failure since univariate approach is often too narrow for the scope of plant breeding (Fikdalski et al., 2007). Breeding a crop for a particular trait involves a complex system of several interacting factors which give rise to several variables which may or not be of interest for breeding. On the other hand, multivariate analysis allows researchers to obtain more information from a data set by considering not only each variable by itself but also the relation among them (Grobe, 2005). According to Beebe, Pell, and Seasholt (1998), multivariate techniques are a key tool in plant breeding programs as it increases selection efficiency.

Among these techniques, principal components analysis (PCA) aims at reducing the set of traits and thus simplifying structurally the data set so that differences between treatments, in principle influenced by a larger set of traits, can be evaluated in twoor three-dimensional spaces of easy geometric interpretation (Cruz et al., 2012). The technique creates orthogonal axes called principal components (PCs), which are linear combinations of the original variables (Leite et al., 2016). Despite the importance of such a tool, application of multivariate methods in castor breeding programs are lacking. One of the few studies which address the topic was Sartori, Silva, and Zanotto (2018), who investigated the efficiency of multivariate methods such as clustering methods (complete link, Euclidian distance and the nearest neighbour method) and PCA to select short-height, high-yielding castor bean cultivars. While dendrograms in clustering methods yielded contrasting results, PCA allowed to efficiently select genotypes based on all desired traits concomitantly. Therefore, the objective of this study was to evaluate PCA as a tool to identify the promising cross combination for commercial cultivation.

\section{Materials and Methods}

The experimental material consists of 33 entries, which includes 20 hybrids, 12 parents and a check (ICH-66) were obtained from the ICAR-IIOR, Hyderabad, India. The present investigation was laid out by randomized complete block design (RCBD) with three replications during kharif, 2019-20 at All India Co-ordinated Research Project on Castor, Zonal Agricultural Research Station, GKVK, Bengaluru.

The complete set of thirty three entries was sown in a single row of 6.0 meter length was assigned to each genotype with 10 dibbles having $60 \mathrm{~cm}$ intra row spacing and $90 \mathrm{~cm}$ inter row spacing. All recommended agronomic practices (dose of NPK (40:40:20 $\mathrm{N}$ : $\mathrm{P}_{2} \mathrm{O}_{5}: \mathrm{K}_{2} \mathrm{O} \mathrm{Kg} / \mathrm{ha}$ ) and plant protection (Sprayed Larvin @ 1g/l and propiconazole @ $0.5 \mathrm{ml} / \mathrm{l}$ for the control of capsule borer and gray mold disease respectively) measures were followed for raising normal crop. The observations were recorded on five randomly selected plants for twelve traits viz., DFF: Days to 50 per cent flowering, DMPS: Days 
to maturity of primary spike, $\mathrm{PH}$ : Plant height $(\mathrm{cm}), \mathrm{NN}$ : Number of nodes up to primary spike, TLPS: Total Length of primary spike (cm), ELPS: Effective Length of primary spike $(\mathrm{cm})$, NC: Number of capsules on primary spike, NES/P: Number of effective spikes per plant, HSW: 100 seed weight (g), HVW: 100 Volume weight (g), SY: Seed yield per plant $(\mathrm{g})$, OC: Oil content $(\%)$. The observations for days to 50 per cent flowering and maturity were recorded on plot basis.

Data was subjected to principal component analysis (PCA) to reduce the number of variables in the original dataset to a more significant set of variables, while maintaining maximum information. Since the original variables do not have the same unit, the correlation matrix was used as a way of prior standardization of the data (cantering on the mean and reducing to the unit of standard deviation). If standardization is not, variables having higher variances would be emphasized in the first components (Wilks, 2006). Eigenvectors, which are coefficients associated positively or negatively with each original variable, were compared to identify how much each PC was explained by each variable and to define those that contributed the most to the formation of each selected PCs. Scores, which are assumed values of each PC for the studied hybrids, are then obtained from the eigenvectors. Finally, such information allows the identification of those hybrids that best stood out in relation to each PC. Data analysis was performed using statistic package Windost at Version 9.3 from indostat services, Hyderaba (India).

\section{Results and Discussion}

The analysis of variance was performed to test the difference amongst parents and hybrids for twelve traits. The results revealed that, highly significant differences among the 33 genotypes for all the characters indicating considerable genetic variation in the material studied (Table 1). A wide range of variation for agronomic parameters in castor was reported by Anjani (2000), Anjani (2012), Gabriela et al., (2019) and Jawahar et al., (2019).

Principal component analysis is a simple non parametric method for extracting relevant information from confusing data sets. With minimum efforts, this provides a roadmap for how to reduce the complex data to a lower dimension to sometimes hidden, simplified structures that often underlines it. Principal component analysis converts a set of correlated variables into a set of values of linearly uncorrelated variables called principal component. In general, plant breeder is interested in keeping only those principal components whose values are greater than 1 . Components with an eigen values of less than 1 account for less variance.

In the present investigation PCA was performed for 12 quantitative traits which yielded five PCs among them only four PCs exhibited more than 1.0 eigen values and showed about $84.34 \%$ variability. Therefore, these four PCs were given due importance for the further explanation. Out of five, the first four principal component having eigen values greater than one with $84.34 \%$ of the total variation among the thirty-three genotype.

The PC 1 explained total variation $33.88 \%$ followed by PC 2 with $27.53 \%$, PC 3 with $13.12 \%$ and PC 4 with $9.81 \%$. PC 1 and PC 2 showed maximum contribution to the total variation are presented in the table 2 and figure 1 . In the figure-1, line diagram explains the percentage of variation associated with each principal component obtained by drawing a graph between Eigen value and principal component number. 
Table.1 ANOVA and Estimates of genetic parameters for twelve morphological descriptors evaluated by 33 castor genotypes

\begin{tabular}{|c|c|c|c|c|c|c|c|c|c|c|c|c|c|}
\hline Source of Variations & DF & DFF & DMPS & $\mathbf{P H}$ & $\mathbf{N N}$ & TLPS & ELPS & NC & NES/P & SY & HSW & HVW & OC \\
\hline Replicate & 2 & $18.575^{* *}$ & $56.030 * *$ & 60.246 & 2.064 & $124.492 *$ & $91.384 * *$ & 174.139 & $11.368^{* *}$ & 562.131 & 13.427 & 16.945 & 4.262 \\
\hline Treatments & 32 & $98.896 * *$ & $306.884 * *$ & $476.006 * *$ & $9.583 * *$ & $119.179 * *$ & $74.358 * *$ & $126.379 * *$ & $13.502 * *$ & $4240.164 * *$ & $72.81 * *$ & $88.938 * *$ & $29.412 * *$ \\
\hline Error & 64 & 2.096 & 6.488 & 19.443 & 0.919 & 29.567 & 15.473 & 57.443 & 1.232 & 474.967 & 6.512 & 5.816 & 5.609 \\
\hline \multicolumn{14}{|l|}{ Genetic Parameters } \\
\hline \multicolumn{2}{|c|}{ Var Environmental } & 2.10 & 6.49 & 19.44 & 0.92 & 29.57 & 15.47 & 57.44 & 1.23 & 474.97 & 6.51 & 5.82 & 5.61 \\
\hline \multicolumn{2}{|c|}{ ECV } & 3.22 & 2.72 & 10.71 & 9.63 & 14.40 & 12.70 & 18.04 & 15.72 & 18.63 & 9.90 & 4.33 & 5.37 \\
\hline \multicolumn{2}{|l|}{ Var Genotypical } & 32.27 & 100.13 & 152.19 & 2.89 & 29.87 & 19.63 & 22.98 & 4.09 & 1255.07 & 22.10 & 27.71 & 7.93 \\
\hline \multicolumn{2}{|l|}{ GCV } & 12.62 & 10.68 & 29.96 & 17.06 & 14.47 & 14.30 & 11.41 & 28.64 & 30.29 & 18.23 & 9.45 & 6.39 \\
\hline \multicolumn{2}{|l|}{ Var Phenotypical } & 34.36 & 106.62 & 171.63 & 3.81 & 59.44 & 35.10 & 80.42 & 5.32 & 1730.03 & 28.62 & 33.52 & 13.54 \\
\hline \multicolumn{2}{|l|}{ PCV } & 13.03 & 11.02 & 31.82 & 19.59 & 20.42 & 19.12 & 21.34 & 32.67 & 35.56 & 20.74 & 10.39 & 8.35 \\
\hline \multicolumn{2}{|l|}{$h^{2}($ Broad Sense $)$} & 0.94 & 0.94 & 0.89 & 0.76 & 0.50 & 0.56 & 0.29 & 0.77 & 0.73 & 0.77 & 0.83 & 0.59 \\
\hline \multicolumn{2}{|c|}{ Genetic Advancement 5\% } & 11.34 & 19.98 & 23.93 & 3.05 & 7.98 & 6.83 & 5.28 & 3.65 & 62.16 & 8.51 & 9.86 & 4.44 \\
\hline \multicolumn{2}{|c|}{ Genetic Advancement 1\%> } & 14.53 & 25.60 & 30.67 & 3.91 & 10.23 & 8.75 & 6.77 & 4.68 & 79.66 & 10.91 & 12.63 & 5.69 \\
\hline \multicolumn{2}{|c|}{ Gen.Adv as \% of Mean $5 \%$} & 25.20 & 21.31 & 58.12 & 30.60 & 21.14 & 22.03 & 12.56 & 51.72 & 53.14 & 33.01 & 17.70 & 10.08 \\
\hline \multicolumn{2}{|c|}{ Gen.Adv as \% of Mean $1 \%$} & 32.29 & 27.31 & 74.48 & 39.22 & 27.09 & 28.23 & 16.10 & 66.28 & 68.10 & 42.30 & 22.68 & 12.91 \\
\hline \multicolumn{2}{|c|}{ C.V. } & 3.22 & 2.72 & 10.71 & 9.63 & 14.40 & 12.69 & 18.03 & 15.72 & 18.63 & 9.90 & 4.33 & 5.37 \\
\hline \multicolumn{2}{|l|}{ S.E. } & 0.84 & 1.47 & 2.55 & 0.55 & 3.14 & 2.27 & 4.38 & 0.64 & 12.58 & 1.47 & 1.39 & 1.37 \\
\hline \multicolumn{2}{|l|}{ C.D. $5 \%$} & 2.36 & 4.16 & 7.19 & 1.56 & 8.87 & 6.42 & 12.36 & 1.81 & 35.55 & 4.16 & 3.93 & 3.86 \\
\hline \multicolumn{2}{|l|}{ C.D. $1 \%$} & 3.14 & 5.52 & 9.56 & 2.08 & 11.79 & 8.53 & 16.43 & 2.41 & 47.24 & 5.53 & 5.23 & 5.13 \\
\hline \multicolumn{2}{|l|}{ General Mean } & 45.00 & 93.73 & 41.18 & 9.96 & 37.76 & 30.99 & 42.03 & 7.06 & 116.98 & 25.79 & 55.71 & 44.08 \\
\hline \multicolumn{2}{|l|}{ Range Lowest } & 35.33 & 81.33 & 25.74 & 8.00 & 22.33 & 21.30 & 28.15 & 3.78 & 33.78 & 13.16 & 42.85 & 35.23 \\
\hline \multicolumn{2}{|c|}{ Range Highest } & 57.33 & 110.67 & 77.78 & 14.22 & 52.29 & 43.67 & 54.66 & 14.34 & 189.41 & 36.09 & 64.17 & 49.18 \\
\hline \multicolumn{2}{|c|}{ Exp Mean next Generation } & 56.34 & 113.70 & 65.11 & 13.01 & 45.74 & 37.81 & 47.30 & 10.71 & 179.14 & 34.30 & 65.56 & 48.52 \\
\hline
\end{tabular}

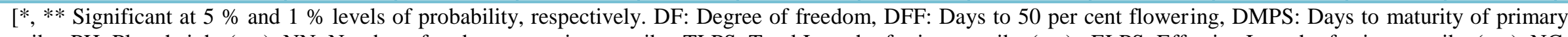

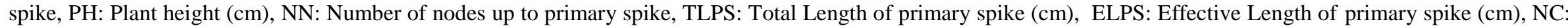

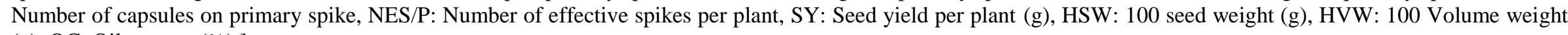
(g), OC: Oil content (\%).]. 
Table.2 Eigen value and percentage of total variance of various principal components

\begin{tabular}{|c|c|c|c|}
\hline Component & Eigen vector & $\begin{array}{c}\text { \% Variance } \\
\text { explained }\end{array}$ & $\begin{array}{c}\text { Cumulative } \\
\text { percentage }\end{array}$ \\
\hline PC1 & 4.066 & 33.88 & 33.88 \\
\hline PC2 & 3.303 & 27.53 & 61.41 \\
\hline PC3 & 1.574 & 13.12 & 74.53 \\
\hline PC4 & 1.177 & 9.81 & 84.34 \\
\hline PC5 & 0.608 & 5.07 & 89.41 \\
\hline
\end{tabular}

Table.3 Component matrix showing latent vectors associated with the five principal components

\begin{tabular}{|c|c|c|c|c|c|}
\hline CHARACTERS & \multicolumn{5}{|c|}{ COMPONENTS } \\
\cline { 2 - 6 } & PC1 & PC2 & PC3 & PC4 & PC5 \\
\hline Days to 50 per cent flowering & 0.43778 & 0.04314 & 0.18520 & 0.03821 & 0.36322 \\
\hline Days to maturity of primary spike & 0.01120 & -0.49475 & 0.18096 & 0.11762 & -0.17140 \\
\hline Plant height (cm) & 0.42835 & 0.10129 & 0.08406 & -0.24815 & -0.18600 \\
\hline Number of nodes up to primary spike & 0.35549 & -0.09826 & -0.03456 & 0.29145 & -0.71760 \\
\hline Total Length of primary spike (cm) & 0.21364 & -0.33558 & 0.40836 & -0.00107 & 0.16805 \\
\hline Effective Length of primary spike (cm) & 0.23900 & -0.40027 & 0.20601 & -0.19738 & 0.22183 \\
\hline Number of capsules on primary spike & 0.07091 & 0.23706 & 0.45040 & -0.43024 & -0.30048 \\
\hline Number of effective spikes per plant & 0.30227 & 0.14479 & -0.43840 & -0.36372 & -0.09676 \\
\hline Seed yield per plant (g) & -0.37167 & -0.14007 & 0.22993 & -0.29447 & -0.30542 \\
\hline 100 seed weight (g) & -0.20366 & 0.36861 & 0.34958 & -0.22345 & 0.05921 \\
\hline 100 Volume weight (g) & -0.34380 & -0.35045 & -0.08096 & -0.11361 & -0.10265 \\
\hline Oil content (\%) & 0.03733 & -0.32426 & -0.37257 & -0.57643 & 0.06873 \\
\hline
\end{tabular}

Table.4 Cluster composition of Castor germplasm based on quantitative characters

\begin{tabular}{|c|c|c|c|}
\hline Clusters & Sub clusters & No. of genotypes & Name of Genotypes \\
\hline \multirow[t]{15}{*}{$\mathbf{I}$} & A & 2 & ICH-1099, ICH-1100 \\
\hline & B & 1 & ICH-404 \\
\hline & $\mathrm{C}$ & 1 & ICH-1106 \\
\hline & $\mathrm{D}$ & 1 & ICH-1104 \\
\hline & $\mathrm{E}$ & 1 & ICH-1097 \\
\hline & $\mathrm{F}$ & 1 & DPC-15 \\
\hline & G & 2 & DCS-104, ICH-824 \\
\hline & $\mathrm{H}$ & 2 & ICH-1101, ICH-1098 \\
\hline & I & 2 & DPC-9, ICH-1094 \\
\hline & $\mathrm{J}$ & 1 & ICH-1107 \\
\hline & K & 1 & ICH-1089 \\
\hline & $\mathrm{L}$ & 1 & ICH-1087 \\
\hline & M & 1 & ICH-1380 \\
\hline & $\mathrm{N}$ & 1 & ICH-1093 \\
\hline & $\mathrm{O}$ & 1 & DCS-94 \\
\hline
\end{tabular}




\begin{tabular}{|c|c|c|c|}
\hline & TOTAL & \multicolumn{2}{|c|}{19} \\
\hline \multirow[t]{6}{*}{ II } & A & 2 & DCS-107, DCS-112 \\
\hline & B & 1 & ICH-1086 \\
\hline & $\mathrm{C}$ & 1 & DCS-119 \\
\hline & $\mathrm{D}$ & 1 & DCS-105 \\
\hline & $\mathrm{E}$ & 2 & ICH-823, ICH-1092 \\
\hline & TOTAL & \multicolumn{2}{|c|}{7} \\
\hline III & A & 1 & DCS-120 \\
\hline IV & A & 1 & DCS-102 \\
\hline $\mathbf{V}$ & A & 2 & ICH-1090, ICH-326 \\
\hline VI & A & 1 & ICH-66 \\
\hline VII & A & 1 & DCS-108 \\
\hline VIII & A & 1 & DCS-89 \\
\hline \multicolumn{2}{|c|}{ GRAND TOTAL } & \multicolumn{2}{|c|}{33} \\
\hline
\end{tabular}

Fig.1 Line diagram showing eigen value for each Principal components

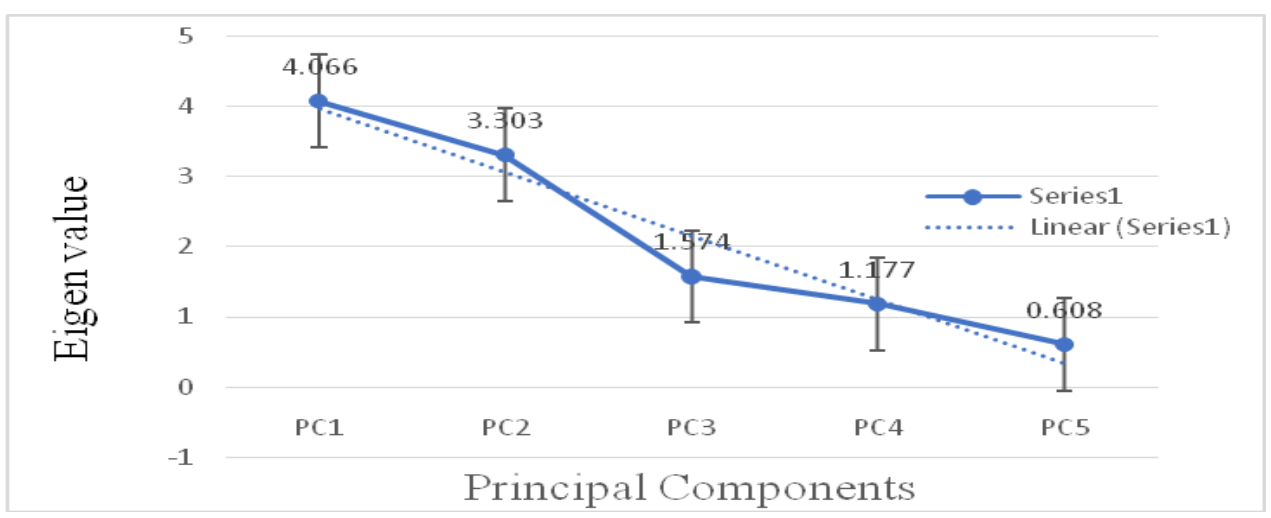

Fig.2 Component matrix showing latent vectors associated with the five principal components

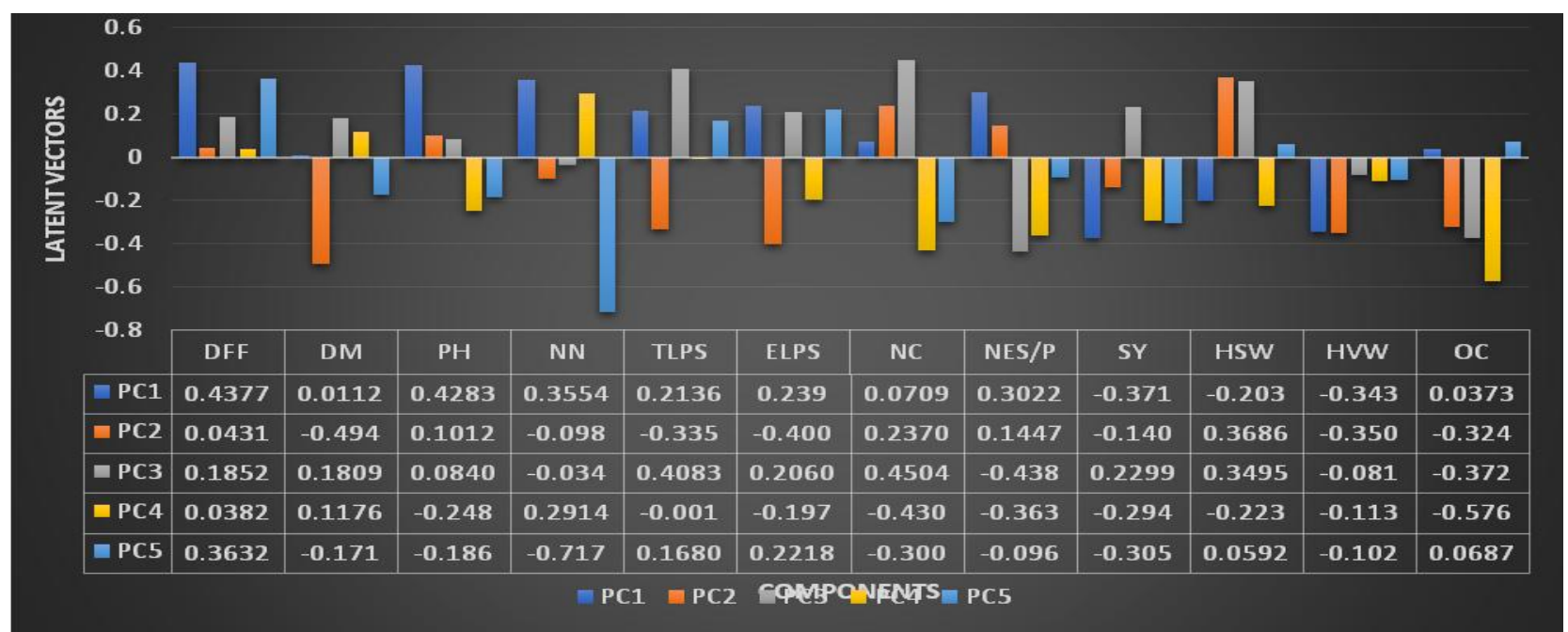

DFF: Days to 50 per cent flowering, DMPS: Days to maturity of primary spike, PH: Plant height $(\mathrm{cm})$, NN: Number of nodes up to primary spike, TLPS: Total Length of primary spike $(\mathrm{cm})$, ELPS: Effective Length of primary spike $(\mathrm{cm}), \mathrm{NC}$ : Number of capsules on primary spike, NES/P: Number of effective spikes per plant, SY: Seed yield per plant (g), HSW: 100 seed weight (g), HVW: 100 Volume weight (g), OC: Oil content (\%) 
Fig.3 Clustering by toucher Method for twelve quantitative characters of Castor

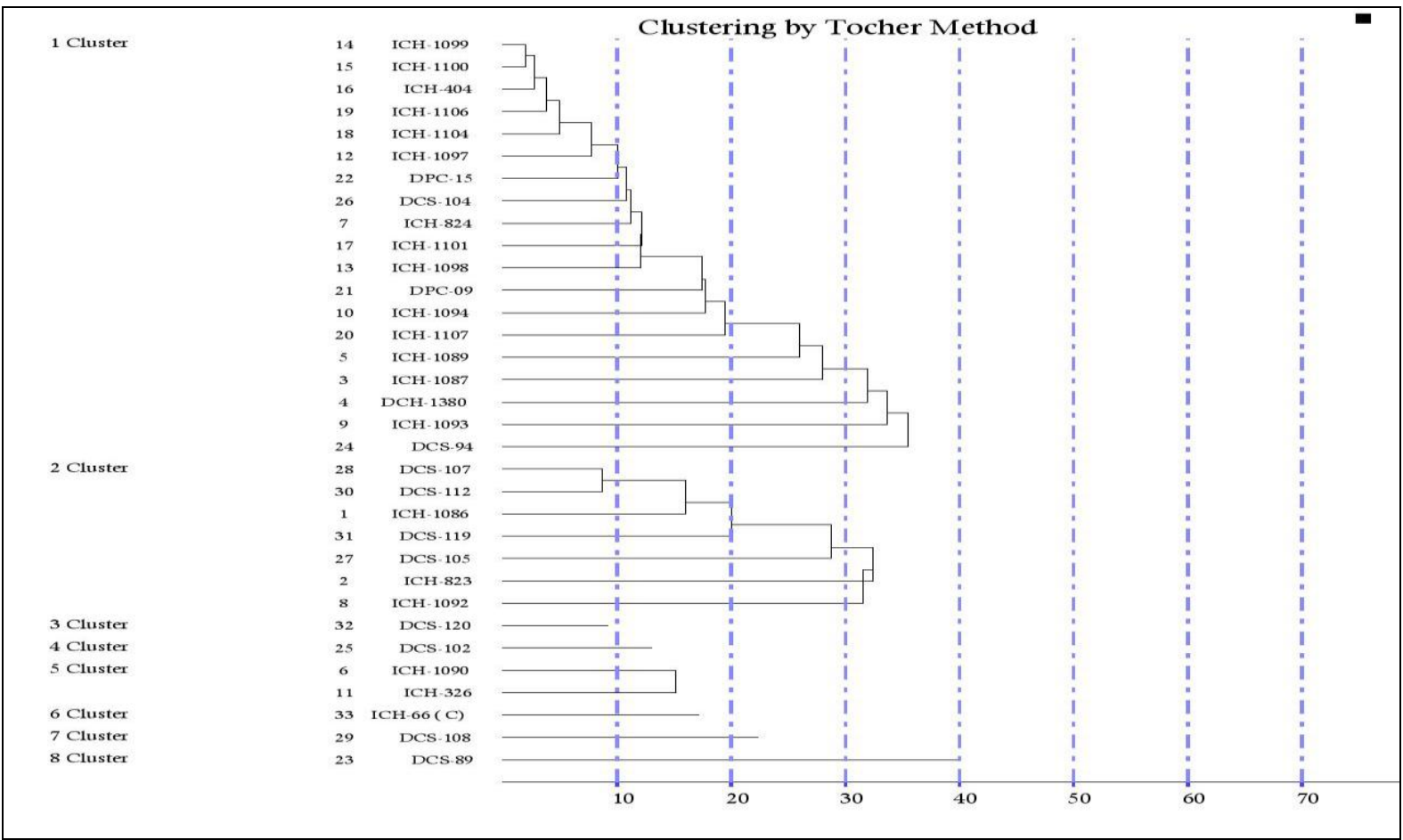

The objective of the principal component analysis is to identify the minimum number of components, which explains maximum variability out of the total variability. $\mathrm{PC} 1$ is the most important component, explained $33.88 \%$ of the total variation and the characters which contributed high on the component were days to 50 per cent flowering, Plant height, number of effective spikes per plant, number of nodes up to primary spike, total Length of primary spike, effective Length of primary spike $(\mathrm{cm})$, number of capsules on primary spike, days to primary spike maturity and percent oil content contributed more towards total variation. The plant traits that separate genotypes along PC1 were major yield contributing characters presented in Table 3 and figure 2. PC2, which is the second important component, explained $27.53 \%$ of total variability and the characters which contribute high on the components were100 seed weight, Number of capsules on primary spike, Number of effective spikes per plant, Plant height and days to 50 per cent flowering. The third component (PC3), explained $13.12 \%$ of total variability and the characters viz., Number of capsules on primary spike, Total Length of primary spike, 100 seed weight, Seed yield per plant, Effective Length of primary spike, Days to 50 per cent flowering, Days to maturity of primary spike and plant height were contributed more for the component. PC4, which is the fourth component, explained $9.81 \%$ of total variability and the characters which contributed high on the component were Number of nodes up to primary spike, Days to maturity of primary spike and Days to 50 per cent flowering. These finding are in confirmation with the earlier findings of Bhand and Patel (1999), Shaheen (2002), Sunil et al., (2005), Amar et al., (2010), Sreelakshmi (2015) reported the first three principal component analysis attributed $95.48 \%$ of variation towards total divergence. Manyasa et al., (2008), Husna et al., (2011), Shivwanshi and Babbar (2017)reported similar traits contributing more to diversity in 
pigeonpea. Similar results were reported by Jawahar et al., (2019) that Principal component (PC) analysis revealed that first three PC axes explained $72.48 \%$ of the total multivariate variation while the first five PC axes explaining $88.94 \%$. These results havean important implication for castor genotype characterization, improvement, agromorphological evaluation and conservation.

\section{Clustering analysis}

Genetic diversity within the castor genotypes was done by Toucher Method for twelve quantitative traitsusing statistic package Windostat Version 9.3. Based on the cluster analysis, thirty three genotypes were grouped into different clusters and sub clusters which is presented in Table 4 and Figure 3. The whole thirty three genotypes divided into eight main clusters. Cluster I consist of 19 genotype which was found to be a largest cluster had sub clusters from $\mathrm{A}$ to $\mathrm{O}$ followed by Cluster II had seven genotypes which divided into five sub clusters. Whereas, cluster III, IV, VI, VII and VIII consists of one genotype in each clusters and they had solitary entries Viz. DCS-120, DCS-102, ICH-66, DCS-108 and DCS-89 respectively. Cluster V also grouped as solitary but had ICH-1090 and ICH-326 genotypes.

Based on values of inter cluster distance, it was found that the highest divergence occurred between cluster II and V (156.96) followed by cluster V and VIII (138.08), cluster I and VIII (110.42) indicating the wider genetic diversity between genotypes of these groups. The cluster VIII involved DCS89which high yielding, cluster II involves DCS-105, DCS-107, DCS-112, and DCS-119 genotypes of pistilate lines M-574,DPC-9 which are cross derivatives of other geographically diverse accessions as per the catalogue of castor germplasm indicating genetic diversity being contributed by geographical diversity or cross combinations involving geographically diverse genotypes (Jawahar et al., 2019). This was in contradiction to studies like Chakrabarty and Banu (1999), and Singh and Srivastava (1978) in castor. Hence, selection of parents from these clusters for hybridization programme would help in achieving novel recombinants. On the other hand, the lowest divergence was noticed between clusters III and IV (16.70) indicating close relationship and similarity for most of the traits of the genotypes in this cluster. The inter cluster distance was higher than the intra cluster distance these results were in agreement with Ramesh et al., (2012), Jawahara et al., (2019) which indicates the existence of substantial diversity among the genotypes.

\section{References}

Amar A, Sakure, Dhaduk H L, Mehta D R, Kavani R H And Madariya R B 2010. Genetic diversity analysis among castor (Ricinus communis 1.) genotypes using morphological markers. Crop Improvement, 37 (2): 99-104.

Anjani K 2012. Castor genetic resources: A primary gene pool for exploitation. Industrial crops and products,35: 1-14.

Anjani K 2000. Catalogue of castor, Vol.1. Directorate of Oilseeds Research, Hyderabad, India.

Beltrão, N. E. de M., Vale, L., and Silva, O. R. F. da (2008). Agricultura Tropical: Quatro décadas de inovaçõestecnológicas, institucionais e políticas. Produção e Produtividade agrícola. Grãos oleaginosos (Vol. 1, pp.753-766). Brasília, Distrito Federal: Embrapa Informação Tecnológica.

Beebe, K. R., Pell, R. J., and Seasholt, M. B. (1998). Chemometrics: A practical guide. New York, NY: JohnWiley and Sons.

Bhand DJ and Patel DR 1999. Inheritance of 
some morphological characters in castor (Ricinus communis L.). GAU. Res. J., 25(1): 103-105.

Bhatt D and Reddy TP 1987. Genetic divergence and heterosis in castor (Ricinus communis L.). Indian Journal of Botany, 10:21-26.

Chakrabarty S K and Banu SS 1999. Genetic diversity in pistillate lines of castor. Indian Journal of Agricultural Sciences, 69(10): 729-730.

Costa, F. X., Beltrão, N. E. de M., Silva, F. E. A., Melo Filho, J. S., and Silva. M. A. (2010). Disponibilidade denutrientes no solo em função de doses de matéria orgânica no plantio da mamona. Revista Verde deAgroecologia e Desenvolvimento Sustentável, 5(3), 204-212.

Costa, M. N. da, Pereira, W. E., Bruno, R. de L. A., Freire, E. C., Nóbrega, M. B. de M., Milani, M., and Oliveira,A. P. de (2006). Divergência genética entre acessos e cultivares de mamoneira por meio de estatísticamultivariada. Pesquisa Agropecuária Brasileira, 41(11), 1617-1622. https://doi.org/10.1590/S0100204X2006001100007

Cruz, C. D., Regazzi, A. J., and Carneiro, P. C. S. (2012). Modelos Biométricos Aplicados ao MelhoramentoGenético. Editora UFV, Viçosa, Brazil.

Fidalski, J., Tormena, C. A., and Scapim, C. A. (2007) Espacialização vertical e horizontal dos indicadores dequalidade para um latossolo vermelho cultivado com citros. Revista Brasileira de Ciência do Solo, 31(1),9-19. https://doi.org/10.1590/S010006832007000100002

Gabriela N. da Piedade, Lucas V. Vieira, Amanda R. P. dos Santos, Deoclecio J. Amorim, Maurício D. Zanotto and Maria M. P. Sartori. (2019), Principal Component Analysis for Identification of Superior CastorBean Hybrids. Journal of Agricultural Science; Vol. 11, No. 9; 2019

Grobe, J. R. (2005). Aplicações da estatística multivariada na análise de resultados em experimentos com solose animais (Master's thesis, Universidade Federal do Paraná, Curitiba).

Husna, A. H. A., M. Haque, and M. Islam. 2011. Research Note Genetic variability in pigeonpea (Cajanus cajan $L$. Millspaugh). Electronic Journal of Plant Breeding 2 (1):117-123.

Jawahar Lal. Jand C. Lavanya 2019. Pattern of Genotypic Diversity in Indigenous Castor (Ricinus communis L.) Genotypes, Int.J.Curr.Microbiol.App. Sci., 8(1): 2465-2471

Leite W. S., Pavan B. E., Alcântara Neto F., Matos Filho C. H. A., Feitosa F. S., and Oliveira C. B. (2016). Multivariate exploratory approach and influence of six agronomic traits on soybean genotypes selection. Nativa, 4, 206-210. https://doi.org/10.14583/23187670.v04n04a04

Manyasa E. O. S. N. Silim S. M. Githiri J. L. Christiansen. 2008. Diversity in Tanzanian pigeonpea [Cajanus cajan (L.) Millsp.]. landraces and their response to environments. Genet. Resour Crop Evol (2008) 55:379-387

Ramesh M, Lavanya C and Brahmeshwar Rao MV 2012. Genetic divergence in some indigenous and exotic germplasm lines of castor (Ricinus communis L.) under rainfed conditions. Indian journal of dryland agricultural research and development, 27 (2): 79- 83.

Sartori, M. M. P., Silva, J. da, and Zanotto, M. D. (2018). Comparison of methods for selection of castor beans lineages. Comunicata Scientiae, 9(4), 687-694.

Scholz, V., and Silva, J. N. da. (2008). Prospects and risks of the rise of castor oil as a fuel. Biomass and Bioenergy,32, 
95-100.

https://doi.org/10.1016/j.biombioe.2007 .08 .004

Singh A and Srivastava AN 1978. Genetic diversity in relation to yield and its components in castor. Indian Journal of Agricultural Sciences, 48: 25-28.

Shaheen AM 2002. Morphological variation within Ricinus communis L. in Egypt: Fruit, Leaf, Seed and Pollen. Pakistan Journal of Biological Sciences, 5(11): 1202-06.

Sreelakshmi, C. A. S. D. 2015. "Germplasm evaluation in pigeonpea, cajanus cajan millisp. Using mahalanobis D2 statistics." Journal of global bioscience 4 (7):2282-2832.

Sunil N Kumar, Ashok Reddy A, Ashokavardhan $\mathrm{P}$ and Varaprasad KS
2005. Collection of diversity in castor (Ricinus communis 1.) germplasm from parts of Andhra Pradesh. Indian Journal of Plant Genetic Resources, 18(3): 13639

Shivwanshi, Renuka, and Babbar. 2017. "Dissection of genetic variability and interrelationship of various quantitative traits of chickpea germplasm lines." International Journal of Current Microbiology and Applied Sciences 6 (10): 166-173.

Weiss, E.A. 2000. Oilseed crops. 2nd ed. Blackwell Science, Oxford.

Wilks, D. S. (2006). Statistical methods in the atmospheric sciences (2nd ed., p. 649). San Diego: Elsevier.

How to cite this article:

Yamanura and Mohan Kumar, R. 2020. Identification of Promising Castor Hybrid Combinations by Principal Component Analysis. Int.J.Curr.Microbiol.App.Sci. 9(09): 11801189. doi: https://doi.org/10.20546/ijcmas.2020.909.146 